\title{
The Effect of Human Immunodeficiency Virus-1 Infection on Low Birth Weight, Mother to Child HIV Transmission and Infants' Death in African Area
}

\author{
Traoré Youssouf ${ }^{*}{ }^{\circledR}$, Téguété Ibrahima1, Dicko Fatoumata Traoré2, Bocoum Amadou1, \\ Fané Seydou ${ }^{1}$, Traoré Tidiani' ${ }^{3}$, Traoré Mamadou Salia ${ }^{4}$, Dao Seydou ${ }^{5}$, Touré Moustapha ${ }^{6}$, \\ Varol Nesrin 7 , Dolo Amadou ${ }^{1}$
}

\author{
${ }^{1}$ Department of Gynaecology and Obstétrics, Gabriel TOURE Teaching Hospital, Bamako, Mali \\ ${ }^{2}$ Department of Pediatics, Gabriel TOURE Teaching Hospital, Bamako, Mali \\ ${ }^{3}$ Department of Gynaecology and Obstétrics, Regional Hospital of Segou, Bamako, Mali \\ ${ }^{4}$ Department of Gynaecology and Obstétrics, Point G Teaching Hospital, Bamako, Mali \\ ${ }^{5}$ Motherhood Unit of "Csref Commune II", Bamako, Mali \\ ${ }^{6}$ Department of Gynaecology and Obstétrics, "Hôpital du Mali” Teaching Hospital, Bamako, Mali \\ ${ }^{7}$ Sydney Gynaecology \& Endometriosis Centre, Sydney Medical School, The University of Sydney, Sydney, Australia \\ Email: ${ }^{\star d r y o u s s o u f . t r a o r e @ g m a i l . c o m ~}$
}

How to cite this paper: Youssouf, T., Ibrahima, T., Traoré, D.F., Amadou, B., Seydou, F., Tidiani, T., Salia, T.M., Seydou, D., Moustapha, T., Nesrin, V. and Amadou, D. (2019) The Effect of Human Immunodeficiency Virus-1 Infection on Low Birth Weight, Mother to Child HIV Transmission and Infants' Death in African Area. Open Journal of Obstetrics and Gynecology, 9, 158-169.

https://doi.org/10.4236/ojog.2019.92017

Received: December 20, 2018

Accepted: January 30, 2019

Published: February 2, 2019

Copyright $\odot 2019$ by author(s) and Scientific Research Publishing Inc. This work is licensed under the Creative Commons Attribution International License (CC BY 4.0).

http://creativecommons.org/licenses/by/4.0/

\begin{abstract}
Background: It is yet a controversy subject whether low birth weight and infant death are associated to human immunodeficiency virus-1 infection. Objective: To appreciate association between low birth weights, mother to child HIV transmission and infant mortality in HIV-1 infected pregnant women delivering between 2011 and 2016. Materials: We conducted 6 years cohort study in urban Mali. Outcome included preterm delivery, small for gestational age, infant survival status and HIV transmission. Comparison concerned women clinical WHO stage, mother viro-immunological status, and newborn anthropometric parameters. Results: HIV-1 infected women who delivered low birth weight newborn were $20.9 \%(111 / 531)$ versus $16.5 \%(1910 / 11.546)$ in HIV negative patients $(\mathrm{p}=0.016)$. CD4 T cell counts low than $350 \mathrm{~T}$ cells count were strongly associated to LBW $(p=0.000$; RR $=3.03 ; 95 \%$ CI $[1.89$ 3.16]). There is no significant association between ART that was initiated during pregnancy $(\mathrm{p}=0.061, \mathrm{RR}=0.02$; CI $95 \%(1.02-1.99)$ ) or during delivery $(\mathrm{p}=0.571$; $R R=1.01$; CI $95 \%(0.10-3.02))$ and LBW delivery. In multivariate analysis $A R T$ regimens containing protease inhibitor (PI) were lone regimens associated with LBW $((\mathrm{p}=0.030 ; \mathrm{RR}=1.001 ; 95 \%$ confidence interval $[1.28-3.80])$. Very low birth weight was statistically associated to
\end{abstract}


women HIV infection (adjusted relative risk, 2.02; $\mathrm{p}=0.000 ; 95 \%$ confidence interval $(2.17-4.10))$. There is no significant difference between mother to child HIV transmission rate in the two HIV-infected pregnant women (10 infected children in group 2: MTCT rate 4.5\%) and 3 infected children in group 1 (MTCT rate: $2.7 \%)(\mathrm{p}=0.56$; RR, 0.59; CI 95\% (0.18 - 4.39)). In multivariate analysis, LBW was associated with infant death $(\mathrm{p}=0.001 ; \mathrm{RR}=$ 2.04; CI 95\% [1.04 - 5.05]). The median weight of infant at the moment of death in group 1 was $851 \mathrm{~g}$ (IQR: 520 - $1833 \mathrm{~g}$ ). Significant relationship was found between infant death among LBW newborn with mother WHO stage 2 $(\mathrm{p}=0.004$; adjusted $\mathrm{RR}=3.22$; CI 95\% [2.25 - 6.00]), CD4 T cells count $<350$ cells $/ \mathrm{mm}^{3}(\mathrm{p}=0.005 ; \mathrm{RR}=2.81 ;$ CI 95\% [1.20 - 4.11]), PI regimens $(\mathrm{p}=$ $0.030 ; \mathrm{RR}=1.00$; CI 95\% [1.28 - 3.80]). Conclusion: We confirm increased risk of low birth weight and mother HIV-1 infection and we identified strongest association between mortality in infant born to HIV-1 infected mother and LBW.

\section{Keywords}

Low Birth Weight, Human Immunodeficiency Virus, Infection, Mother to Child Transmission, Newborn Death, Mali

\section{Introduction}

The main risk in human immunodeficiency virus positive pregnant women widely studied is the transmission of the virus to newborn [1]. The potential adverse effects of HIV-1 infection during pregnancy on weight at birth and infant mortality are few studies, mostly from African English speaking countries. Another possible risk is the influence of this infection on neonate anthropometric characteristics [2] [3]. But this is a controversy subject in scientific domain. Indeed for some authors [4] [5] [6] [7], children born to HIV infected mothers have higher risk of LBW. A study that took place in Cote d'Ivoire confirmed that this LBW is associated to antiretroviral treatment (ART) [8] while for Minkoff [9], there is no relationship between HIV and LBW.

Independently of infant HIV infection, LBW constitutes one of the strongest causes of newborn mortality [2] [10]. In populations with a high prevalence of HIV infection, maternal HIV, status and LBW are likely to be important determinants of child survival [11]. Is women HIV infection an additional risk factor of infant death? Most of studies examined association between LBW in HIV infected patients without discrimination of types of the virus. Also, few surveys about LBW among HIV-1 infected women examined the association between LBW and mother to child HIV transmission (MTCT) and risk factors of newborn outcome.

A better understanding of risk factors of LBW born to HIV-1 infected mother and the relationship between mother to child HIV transmission (MTCT) and LBW would help in developing countries to undertake interventions to reduce 
LBW and its consequences in HIV positive women and so to reduce HIV transmission to child born to HIV infected mother in that situation. The particularities of this study are: firstly, that study took place in a West African French speaking country where this area has not been thoroughly studied; secondly, it took place in a low HIV prevalence country and thirdly this study is about LWB and newborn death among HIV-1 infected women. We reported the results of the relationship between HIV-1 maternal infection and anthropometric characteristics of the child at birth. The objectives of our study were to determine risk factors of LBW among HIV-1 infected mother, to evaluate newborn death risk factors and to determine the rate of HIV transmission from mother to child in this LBW delivery context.

\section{Materials and Methods}

\subsection{Study Setting and Population}

This study was conducted in Gabriel Touré teaching hospital that is a tertiary care referral center in Bamako, Mali. This hospital is the first site of prevention to child HIV transmission (PMTCT) in Mali and contributes in training and researching in HIV domain. It receives patients from other health centers, as well as providing antenatal care services among HIV infected pregnant women from urban and rural areas surrounding Bamako.

This is a cohort study conducted from existing data in a database of pregnant women followed in the department of gynecology and obstetrics in Gabriel Touré Teaching Hospital. It took place from $1^{\text {st }}$ January 2011 to December $31^{\text {st }}$, 2016 (6 years). The study population included all the three groups of patients below and their newborns enrolled during the study period and followed until final pediatric HIV status could be determined (18 months). The different groups of patients have been obtained by randomization. Three groups have been performed and compared:

- Group 1 representing by HIV-1 infected women who delivered newborns whose weigh less than $2500 \mathrm{~g}$;

- Group 2 concerning HIV-1 infected pregnant women who delivered newborns with weight $\geq 2500 \mathrm{~g}$;

- Group 3 representing by HIV negative pregnant women who delivered newborns whose weight is less than $2500 \mathrm{~g}$.

Birth weights below $2.500 \mathrm{~g}$ were classed as "low", body lengths less than $47 \mathrm{~cm}$ at birth were described as "small birth size" and head circumferences $<33 \mathrm{~cm}$ were classed as "small". Premature birth is defined by all delivery between 28 and 36 weeks (wk) and 6 days (d) or newborn weight $<2500 \mathrm{~g}$ and body length $<$ $47 \mathrm{~cm}$. Very LBW was defined by newborn weight between 520 to $1500 \mathrm{~g}$ at birth and hypotrophy was defined by new born weight $\geq 2500 \mathrm{~g}$ and body length $<47 \mathrm{~cm}$.

A monthly staff with PMTCT program members (obstetricians, pediatricians, virologists, specialists of HIV management, psycho social team members, pharmacy officers) was organized to appreciate patients clinical informations and to 
decide their delivery way and the calendar of following of the future babies.

Data were collected from our obstetric files, daily updating by a midwife and an obstetrician performed in data management. The supports used to complete this database are: complete obstetric files, complete neonatal PMTCT unit files, on-call registries of midwives, surgical reports, admissions records for emergency unit and hospital birth registries. The children lost to follow-up were retired from the analysis.

All patients were screened for highly active antiretroviral treatment (HAART) eligibility according world health organization (WHO) stages, absence of medical contraindications to HAART, adherence of treatment, mode of feeding (formula or breast feeding) of future baby. According eligibility criteria, pregnant HIV-1 infected women initiated HAART.

CD4 $\mathrm{T}$ cell count and viral load (VL) were measured upon enrolment and around $32-34$ wks of gestation from the first day of last menstruation date.

We didn't include in this study pregnant women with diseases classically responsible to LBW (high blood pressure, anemia, sickle cell disease, twin pregnancy) or macrosomia (diabetes). We didn't include also HIV-2 and HIV1 +2 infected pregnant women.

Study variables analyzed were: newborns anthropometric characteristics (birth weight, body length and head circumference), maternal viral load, maternal WHO stage, antiretroviral treatment (ART) regimens of the mothers, newborn type of feeding, sex of newborn, MTCT HIV rate, HIV status of newborn, age of newborn at death. The quantification limit of VL was $<50$ copies $/ \mathrm{ml}$.

\subsection{Study Design and Statistical Analysis}

Statistical Package for the Social Sciences (SPSS) 17 was used for data analysis. Comparison of qualitative variables was made by using the chi square test or Fisher exact test, the quantitative variables comparison was done by Student's $t$ test. Logistic regression has been also used to appreciate risk factors of LBW. The survival analyses were conducted in HIV infected groups (1 and 2) and the Kaplan-Meier method was used to estimate association between LBW and HIV infection, HIV risk transmission and newborn or infant death. Results have been expressed in percentage with their relative risk (RR), 95\% confidence interval $\left(\mathrm{CI}_{95}\right)$. p value $<0.05 \%$ considered significant.

\section{Results}

Of 12.077 births recorded in this study within 531 cases of pregnant women HIV-1 infected (4.4\%). Of the 531 HIV-1 positive pregnant women, we randomized 111 women who delivered newborn with LBW (group e1) and 222 HIV-1 positive pregnant who delivered newborn whose weight $\geq 2500 \mathrm{~g}$ (group 2). Of the remaining 11.546 patients we randomized $222 \mathrm{HIV}$ negative pregnant women who delivered newborn weight $<2500 \mathrm{~g}$ (group 3). The rate of newborns with LBW in the study has been 20.9\% (111/531); during the same period the rate of newborn whose birth weight among HIV negative pa- 
tients was $16.5 \%(1910 / 11.546)(\mathrm{p}=0.016)$.

The analysis of Table 1 that presents data about relation between the CD4 T Cell, Viral load (VL), status of newborn, weight at birth, sex of the newborn, newborn death, HAART regimen and moment of ART initiation (Univariate and multivariate Analysis) in the area showed: CD4 T cell counts low than $350 \mathrm{~T}$ cells count was strongly associated to LBW ( $p=0.000$; RR, 3.03; 95\% CI [1.89 3.16]). Average rate of CD4 T cells counts in group 1 was 570 cells $/ \mathrm{mm}^{3}$ (extreme values $=11$ and 1099 cells $\left./ \mathrm{mm}^{3}\right)$. In group 2, CD4 T cells count average rate was 541 cells $/ \mathrm{mm}^{3}$ (extreme values $=2$ and $1082 \mathrm{cells} / \mathrm{mm}^{3}$ ).

The VL was undetectable in group 1 in 58.3\% (28 cases/48) and 61.7\% (66 cases $\left./ 10^{7}\right)$ in group $2(\mathrm{p}=0.416)$.

HAART was initiated in group 1 at a median of gestational week of $31 \mathrm{wk}$ with an interquartile range (IQR) of $26-34 \mathrm{wk}$. For group 2 it was initiated at a median of gestational week of $32 \mathrm{wk}$ (IQR = 27 - $33 \mathrm{wk}$ ). In the both groups, VL and sex of newborn were not related to LBW. There is no significant association between ART that was initiated during pregnancy $(\mathrm{p}=0.061, \mathrm{RR}, 0.02 ; 95 \% \mathrm{CI}$ [1.02 - 1.99]) or during delivery ( $p=0.571$; RR, 1.01; 95\% CI [0.10 - 3.02]) and LBW delivery.

In multivariate analysis ART regimens containing protease inhibitor (PI) were lone regimens associated with LBW ( $\mathrm{p}=0.030$; RR, 1.001; 95\% CI [1.28 - 3.80]). Very low birth weight was statistically associated to women HIV-1 infection ( $\mathrm{p}=$ 0.010 ; RR, 1.13; 95\% CI [1.05 - 5.07]); this difference persisted after adjustment (adjusted relative risk, 2.02; $\mathrm{p}=0.000 ; 95 \% \mathrm{CI}$ [2.17 - 4.10]). In group 1 average weight of newborns was $1996.4 \mathrm{~g}$ (extremes values: $520 \mathrm{~g}$ and $2480 \mathrm{~g}$ ) versus $2599.0 \mathrm{~g}$ in group 2 (extremes values: 2510 and $4120 \mathrm{~g}$ ).

Other anthropometric data showed that $67.5 \%$ and $60.4 \%$ of children in group 1 had respectively body length and head circumference below standard measurement compared to newborns of group $3(\mathrm{p}=0.000)$.

There is no significant difference between mother to child HIV transmission rate in the two HIV-1 infected pregnant women (10 infected children in group 2: MTCT rate $4.5 \%)$ and 3 infected children in group 1 (MTCT rate: $2.7 \%)$ (p = 0.56; RR, 0.59; 95\% CI [0.18 - 4.39]).

During follow-up, 17 newborn and infant deaths in the group 1 and 13 newborn and infant deaths in group 2 were reported. No statistically significant difference was found according to infant death and infant feeding practice ( $\mathrm{p}=$ 0.171 ). In multivariate analysis, LBW was associated with infant death ( $\mathrm{p}=$ 0.001 ; RR, 2.04; 95\% CI [1.04 - 5.05]). The median weight of infant at the moment of death in group 1 was $851 \mathrm{~g}$ (IQR: 520 - $1833 \mathrm{~g}$ ).

Table 2 showed significant relationship between infant death among LBW newborn with mother WHO stage 2 ( $\mathrm{p}=0.004$; adjusted RR, 3.22; CI [2.25 6.00]), CD4 T cells count $<350$ cells $/ \mathrm{mm}^{3}$ ( $\mathrm{p}=0.005 ; \mathrm{RR}, 2.81 ; 95 \%$ CI [1.20 4.11]), PI regimens ( $\mathrm{p}=0.030$; $\mathrm{RR}, 1.001 ; 95 \% \mathrm{CI}[1.28$ - 3.80]). Among HIV infected children in the both groups, we recorded two deaths of children in the group 1 (2/17 being $11.8 \%)$ and 3 in the group 2 (3/13 being $23.1 \%)$. 
Table 1. Relation between the CD4 T Cell, Viral load (VL), status of newborn, weight at birth, sex of the newborn, newborn death, HAART regimen and moment of ART initiation at Gabriel Touré Teaching Hospital from January 2011 to 2016 (Univariate and adjusted risk relative analysis).

\begin{tabular}{|c|c|c|c|c|c|c|c|c|c|}
\hline Variables & $\begin{array}{c}\text { Group } 1 \\
\mathrm{~N}=111 \\
(\%)\end{array}$ & $\begin{array}{c}\text { Group } 2 \\
\mathrm{~N}=222 \\
(\%)\end{array}$ & $\begin{array}{c}\text { Group } 3 \\
\mathrm{~N}=222 \\
(\%)\end{array}$ & $\mathrm{p}$-value & $\mathrm{RR}_{95 \%}$ & $\mathrm{CI}$ & $\mathrm{p}$-value & Adjusted RR & CI \\
\hline \multicolumn{10}{|l|}{ Newborn Death } \\
\hline Yes & $17(15.3)$ & $13(5.9)$ & $2(0.9)$ & 0.002 & 4.14 & $(2.19-4.21)$ & 0.001 & 2.04 & $(1.04-5.05)$ \\
\hline No & $94(84.7)$ & $209(94.1)$ & $220(99.1)$ & 0.056 & 0.12 & $(0.90-2.10)$ & - & - & - \\
\hline \multicolumn{10}{|l|}{ CD4 T Cells $/ \mathrm{mm}^{3}$} \\
\hline$<350$ & $76(68.5)$ & $49(22.1)$ & - & 0.000 & 3.03 & $(1.89-3.16)$ & 0.001 & 2.04 & $(1.04-5.05)$ \\
\hline$[350-500]$ & $16(4.4)$ & $43(19.4)$ & - & 0.020 & 5.34 & $(2.89-9.02)$ & 0.042 & 0.21 & $(0.94-6.00)$ \\
\hline$\geq 500$ & $19(17.1)$ & $130(58.5)$ & - & 0.002 & 4.07 & $(1.57-4.00)$ & 0.059 & 1.00 & $(0.33-1.88)$ \\
\hline \multicolumn{10}{|c|}{ Viral Load (copies/ml) } \\
\hline$<50$ & $28(58.3)$ & $66(61.7)$ & - & 0.416 & 0.51 & $(0.60-1.93)$ & 0.78 & 0.49 & $(0.81-1.01)$ \\
\hline$\geq 50$ & $20(41.7)$ & $41(38.3)$ & - & 0.510 & - & - & - & - & - \\
\hline \multicolumn{10}{|l|}{ Status of newborn } \\
\hline Hypotrophy & $70(63.1)$ & - & $97(47.6)$ & 0.004 & 2.05 & $(1.12-1.36)$ & 0.000 & 3.00 & $(1.032-6.10)$ \\
\hline Premature & $41(36.9)$ & - & $124(55.9)$ & 0.031 & 1.34 & $(1.26-2.45)$ & 0.052 & 0.34 & $(0.17-1.53)$ \\
\hline \multicolumn{10}{|l|}{ Sex of newborn } \\
\hline Male & $62(55.9)$ & $121(54.5)$ & $113(50.9)$ & 0.070 & 0.24 & $(0.70-2.20)$ & - & - & - \\
\hline Female & $49(44.1)$ & $101(45.5)$ & $109(49.1)$ & 0.821 & 0.20 & $(0.40-1.90)$ & - & - & - \\
\hline \multicolumn{10}{|l|}{ Weight at Birth (g) } \\
\hline$[520-1500]$ & $47(42.3)$ & - & $83(37.4)$ & 0.010 & 1.13 & $(1.05-5.07)$ & 0.000 & 2.02 & $(2.17-4.10)$ \\
\hline$[1500-2500]$ & $64(57.7)$ & - & $139(62.6)$ & 0.611 & 1.00 & $(1.00-3.10)$ & - & - & - \\
\hline \multicolumn{10}{|c|}{ ART Initiation Moment } \\
\hline Before Pregnancy & $49(44.1)$ & $32(14.4)$ & - & 0.036 & 3.20 & $(2.13-5.22)$ & 0.006 & 2.11 & $(1.09-3.99)$ \\
\hline During Pregnancy & $51(45.9)$ & $166(74.8)$ & - & 0.041 & 0.01 & $(1.01-2.02)$ & 0.061 & 0.02 & $(1.02-1.99)$ \\
\hline During Delivery & $8(7.2)$ & $24(10.8)$ & - & 0.571 & 1.01 & $(0.10-3.02)$ & - & - & - \\
\hline \multicolumn{10}{|c|}{ HAART Regimens Used } \\
\hline $2 \mathrm{INTI}+1 \mathrm{INNTI}$ & $84(75.7)$ & $191(86.0)$ & - & 0.640 & 0.61 & $(0.39-3.19)$ & - & - & - \\
\hline $2 \mathrm{INTI}+1 \mathrm{IP}$ & $21(18.9)$ & $28(12.6)$ & - & 0.030 & 1.01 & $(1.28-3.80)$ & 0.030 & 1.001 & $(1.28-3.80)$ \\
\hline 3INTI & $6(5.4)$ & $3(1.4)$ & - & 0.041 & 1.21 & $(1.99-2.11)$ & 0.058 & 1.51 & $(0.99-3.66)$ \\
\hline \multicolumn{10}{|l|}{ Infant HIV Status } \\
\hline Infected & $3(2.7)$ & $10(4.5)$ & - & 0.56 & 0.59 & $(0.18-4.39)$ & - & - & - \\
\hline Uninfected & $108(97.3)$ & $212(95.5)$ & - & 0.79 & 0.76 & $(0.20-2.40)$ & - & - & - \\
\hline
\end{tabular}


Table 2. Relation between LBW and newborn death in multivariate analysis according CD4 T Cell, Viral load (VL), mother WHO stage, status of newborn, weight at birth, sex of the newborn, newborn death, HAART regimen and moment of ART initiation at Gabriel Touré Teaching Hospital from January 2011 to 2016.

\begin{tabular}{|c|c|c|c|c|c|}
\hline \multirow[b]{2}{*}{ Variables } & \multicolumn{5}{|c|}{ Infant Death } \\
\hline & $\begin{array}{c}\text { Group 1 } \\
\mathrm{N}=17(\%)\end{array}$ & $\begin{array}{c}\text { Group 2 } \\
\mathrm{N}=13(\%)\end{array}$ & $\mathrm{p}$-value & Adjusted RR & $\mathrm{CI}$ \\
\hline \multicolumn{6}{|l|}{ Mother WHO Stage } \\
\hline 1 & $2(11.8)$ & $1(7.7)$ & & & \\
\hline 2 & $7(41.2)$ & $5(38.5)$ & 0.004 & 3.22 & $(2.25-6.00)$ \\
\hline 3 & $5(29.4)$ & $3(23.1)$ & & & \\
\hline 4 & $3(17.6)$ & $4(30.8)$ & & & - \\
\hline \multicolumn{6}{|l|}{ CD4 T Cells $/ \mathrm{mm}^{3}$} \\
\hline$<350$ & $9(53.0)$ & $6(46.1)$ & 0.005 & 2.81 & $(1.20-4.11)$ \\
\hline$[350-500]$ & $4(23.5)$ & $4(30.8)$ & 0.009 & 0.06 & $(0.38-3.44)$ \\
\hline$\geq 500$ & $4(23.5)$ & $3(23.1)$ & 0.724 & 0.11 & $(0.56-1.99)$ \\
\hline \multicolumn{6}{|l|}{ VL a Birth (copies/ml) } \\
\hline$<50$ & $11(58.3)$ & $8(61.7)$ & & & - \\
\hline$\geq 50$ & $6(41.7)$ & $5(38.3)$ & & & - \\
\hline \multicolumn{6}{|l|}{ ART Initiation Moment } \\
\hline Before Pregnancy & $49(44.1)$ & $32(14.4)$ & 0.006 & 2.11 & $(1.09-3.99)$ \\
\hline During Pregnancy & $51(45.9)$ & $166(74.8)$ & 0.061 & 0.02 & $(1.02-1.99)$ \\
\hline During Delivery & $8(7.2)$ & $24(10.8)$ & 0.703 & 0.23 & $(0.04-1.87)$ \\
\hline \multicolumn{6}{|l|}{ HAART Regimens Used } \\
\hline 2INTI + 1INNTI & $9(75.7)$ & $8(86.0)$ & 0.640 & 0.61 & $(0.39-3.19)$ \\
\hline $2 \mathrm{INTI}+1 \mathrm{IP}$ & $6(18.9)$ & $5(12.6)$ & 0.030 & 1.001 & $(1.28-3.80)$ \\
\hline $3 \mathrm{INTI}$ & $2(5.4)$ & $0(0.0)$ & 0.041 & 1.211 & $(0.99-2.11)$ \\
\hline \multicolumn{6}{|l|}{ Sex of Newborn } \\
\hline Male & $9(55.9)$ & $7(54.5)$ & 0.070 & 0.24 & $(0.21-1.40)$ \\
\hline Female & $8(44.1)$ & $6(45.5)$ & 0.821 & 0.20 & $(0.40-1.90)$ \\
\hline \multicolumn{6}{|l|}{ Infant Feeding } \\
\hline Formula Feeding & $8(47.1)$ & $5(38.5)$ & 0.171 & 0.07 & $(0.23-1.96)$ \\
\hline Breast Feeding & $9(52.9)$ & $8(61.5)$ & & & \\
\hline \multicolumn{6}{|l|}{ Infant HIV Status } \\
\hline Infected & $2(11.8)$ & $3(23.1)$ & & & \\
\hline Uninfected & $15(88.2)$ & $10(76.9)$ & 0.405 & 0.64 & $(0.67-2.30)$ \\
\hline
\end{tabular}




\section{Discussion}

Our study demonstrated clearly that LBW is higher among HIV-1 infected pregnant women $(20.9 \%)$ than HIV-negative one $(16.5 \%)$. It showed also that the main risk factors of LBW among HIV-1 infected mother were low CD4 T cells count, ART regimen before beginning of pregnancy and ART regimen containing PI (Table 1). Hypotrophy and birth weight less than $1500 \mathrm{~g}$ were associated to mother HIV-1 infection.

Few studies in West Africa examined the association between LBW and mother HIV-1 infection. In a cross-sectional study conducted by Sombié [3] in Bobo-Dioulasso from January 1995 to May 1996, LBW was more frequent among children born to HIV-infected mothers than among those born to uninfected mothers $(23.37 \%$ versus $15.6 \%$; $\mathrm{p}=0.006)$. In the multivariate analysis, he demonstrated that mother HIV infection was a risk factor of LBW ( $p<0.001$ ). Data from Cote d'Ivoire [8] about ART and prevention of peripartum and postnatal HIV transmission in West Africa and from Senegal [12] about PMTCT, found association between LBW and mother HIV infection without discrimination between the types of virus. For Tonwe [8], multivariate analysis showed low birth weight $(<2500 \mathrm{~g})$ was the only factor associated with acquisition of HIV infection, with an adjusted hazard ratio of 5.63 ( $p=0.006$; 95\% CI [1.62 19.49]). Other studies confirm this relationship between LBW and HIV infection. Indeed for Ratchanee [13] in Thailand, kamenga [14] in Kinshasa and Martin [15] in USA, LBW was strongly associated to maternal HIV infected status. In a study that evaluated maternal HIV infection and other sexually transmitted diseases and LBW, Kamenga [14] reported a newly double prevalence of LBW ( $21 \%$ versus $11 \%$, odds ratio 2.1 ; $95 \%$ CI [1.3 - 3.5]). However some authors believed there is no relationship between LBW and mother HIV infection. It is the case in Minkof [9] study that did not found any influence between child birth weight and HIV infection although the growth retardation is common among newborns from HIV positive women.

In Africa, particularly in Mali, pregnant HIV infected women usually consult later when they had advanced HIV disease, exposing them to opportunistic or repeat infections. These infections led to premature births that were more frequent in our patients in group 1 whose CD4 T cells count rate was three times lower. In Tanzania, Dreyfus [16] found in a multivariate-adjusted linear regression that CD4 cell count $<200$ cells $/ \mathrm{mm}^{3}$ was significantly associated with LBW. However, for Kamenga [14] maternal T4 lymphocyte level is not associated with LBW.

Analysis of Table 1 shows that the proportion of LBW was not different if ART is initiated during pregnancy or during delivery. When treatment is started early, children were smallest at birth [17]. Our results are confirmed by a meta-analysis that found after adjusting for several factors, HAART used pre-conception was associated with an increased risk for preterm delivery ( $\mathrm{p}=0.009$; adjusted OR, 5.0; 95\% CI [1.5 - 17.0]) and LBW ( $\mathrm{p}=0.001$; OR, 3.6; 95\% CI [1.7 - 7.7]) 
[18]. Indeed, we believe that if HIV testing is done before the beginning of pregnancy and when treatment is instituted early, this would improve the immune status of the patient and then reduce the risk and recurrence of opportunistic infections and then avoid LBW. Some authors [17] [19] incriminated PI in the occurrence of low birth weight while for Tonwe [8] antiretroviral treatment, irrespective of class, is more associated with weight at birth. This risk is lower among mothers treated with drugs containing no PI (OR $=0.58$; 95\% CI. [0.41 0.84]) compared to the group of women treated with mono therapy [19]. But it was higher in women treated with PI and women treated without PI [19]. So, he concluded that delivery of very LBW was associated with the use of PI although this association was not significant [19]. Women receiving PI-containing drugs had a deeper immunological status more than those who had not been treated by PI regimen [17]. Therefore, they CD4 T cells count rate was so lower their health requires a prescription of powerful antiretroviral regimen to make viral load undetectable and to reduce the frequency of opportunistic infections.

Regarding the term of pregnancy and HAART regimen, our results were not consistent with data of the literature which reported preterm and very preterm newborns rates significantly associated with antiretroviral treatment [17]. Our study preterm delivery rate is higher than that reported in France [17] (10.5\% including 2 cases of mother treated by PI), USA [15] (19\%) and Burkina Faso (2 cases) [3]. Data from Côte d'Ivoire [8] found no significant difference in the rates of premature births (gestational age $<37 \mathrm{wk}$ ) between the two groups comparing short and long treatments regimens $(7.8 \%$ and $7.9 \%, \mathrm{p}=1.00)$. However a higher proportion of LBW $(<2500 \mathrm{~g})$ was observed in neonates whose mothers had received HAART $(26.3 \%)$ compared to patients having received a short course of ART $(12.4 \%)$ for PMTCT regimen $(\mathrm{p}<0.0001)$. These differences persisted after adjusting for maternal body mass index, CD4 T cells count and the WHO clinical stage [8]. In Malawi, prematurity rate was higher in women on highly active antiretroviral therapy (HAART) $(14.1 \%, 476 / 3384)$ than in women on mono/dual therapy $(10.1 \%, 107 / 1061)$, even after adjusting for ethnicity, maternal age, clinical status and injecting drug use as use as the source of HIV acquisition ( $\mathrm{p}=0.001$; adjusted OR, 1.51, 95\% CI [1.19 - 1.93]). Delivery at $<35$ weeks was even more strongly associated with HAART ( $<<0.001$; OR, 2.34; 95\% CI [1.64 - 3.37]). For Townsend [20], the effect was the same whether or not HAART included a protease inhibitor. In a study that analyzed adverse birth outcome in HIV infected women in Botswana, Chen [21] reported that patients continuing HAART from before pregnancy had higher odds of preterm delivery (adjusted OR, 1.2; 95\% CI [1.1, 1.4]), small newborn for gestational age (adjusted OR, 1.8; 95\% CI $[1.6,2.1])$. In the same survey, among women initiating antiretroviral therapy in pregnancy, HAART use was associated with higher odds of preterm delivery (adjusted OR, 1.4; 95\% CI [1.2, 1.8]), small newborn for gestational age (adjusted OR, 1.5; 95\% CI [1.2, 1.9]) [21]. So, he concluded HAART receipt during pregnancy was associated with increased preterm delivery and small gestational age [21]. 
In Bobo-Dioulasso, mean birth weight, birth size and head circumference did not significantly differ between the children of HIV-infected and uninfected mothers [3]. Maternal HIV infection appears to be associated with LBW and small birth size [3].

The rate of HIV transmission from mother to child was twice lower than women who delivered normal weight newborns. However there was no significant difference between mother to child HIV transmission rate in the two HIV-1 infected pregnant women (MTCT rate 4.5\%) and LBW group 1 (MTCT rate: 2.7\%) ( $\mathrm{p}=0.56$; RR, 0.59; 95\% CI [0.18 - 4.39]). All infected newborns were breastfed and had not received optimal management [17], pattern observed among Milogo-Traore [22] and Khuong-Josses studies [17]. Breastfeeding that is not formally indicated in developed countries is often the only logical choice in our limited resources countries to feed these children living generally in a precarious situation.

Premature birth is a cause of MTCT if maternal treatment is initiated late (after 28 weeks of gestation). When it occurs, HAART drugs had not enough time to decrease the mother's plasma HIV viral load, enhance immune function and reduce dramatically the HIV transmission to the newborn [8]. The viral load, sex of newborn, CD4 cells count $\geq 350$ cells $/ \mathrm{mm}^{3}$, 3INTI and 2 INRTI plus 1 INNRTI regimens were not associated with the occurrence of LBW. VL was undetectable in similar rate in both groups of HIV infected women in our study.

Another risk related to low birth weight in HIV infected mother is newborn and infant death [2]. During the 18 months follow-up, we reported 17 newborn and infant deaths in the group 1 and 13 newborn and infant deaths in group 2. Infant death was two time more associated to newborn LBW (adjusted RR = 2.04). In multivariate analysis, LBW was associated with newborn and infant death $(\mathrm{p}=0.01$; RR, 3.55; 95\% CI [1.22 - 4.19]). The main risk factors of child death were mother WHO stage 2 ( $\mathrm{p}=0.004$; adjusted RR, 3.22; 95\% CI [2.25 $6.00]$ ), PI regimens ( $p=0.030$; RR, 1.001; 95\% CI [1.28 - 3.80]). Among HIV infected children in the both groups, we recorded two deaths of children in the group 1 (2/17 being $11.8 \%)$ and 3 in the group 2 (3/13 being 23.1\%). No statistically significant difference was found according to infant death and infant feeding practice $(\mathrm{p}=0.171)$. These results are confirmed by Tanzania study conducted by Ruilan [2] that found that after adjustment, LBW was associated with a 2-fold increased risk of infant mortality ( $\mathrm{RR}=2.40$; $95 \% \mathrm{CI} 1.45$ - 3.95). Infant death in our study was negatively influenced by LBW and mother's CD4 T cells count $<350$ cells $/ \mathrm{mm}^{3}$ ( $\mathrm{p}=0.005$; RR, 2.81; CI [1.20 - 4.11]), contrarily to MTCT of the virus that was not related to LBW (Table 2); but this conclusion could be discussed because of the very low rate of HIV infant infection in our study.

\section{Conclusion}

The occurrence of LBW in HIV-1 infected women is relatively more frequent than HIV negative mothers. These newborn low birth weights are mainly related 
to low CD4 T cells count $\left(<350\right.$ cells $\left./ \mathrm{mm}^{3}\right)$, ART regimens containing PI, and ART initiated before beginning of pregnancy. Newborn death was strongly related to LBW in our patients. No relationship has been found between newborn low birth weight and MTCT of HIV. These results confirm that efforts to reduce the incidence of LBW are necessary to enhance the benefices of PMTCT program.

\section{Conflicts of Interest}

There is no conflict of interest for authors in that submitted manuscripts.

\section{References}

[1] Traoré, Y., Dicko Traoré, F., Téguété, I., Mounkoro, N., Théra, A., Sissoko, A., Diallo, A., Dolo, T., Bagayogo, M., Djiré, Y.M., Koné, D., Doumbia, D., Koné, O., Tinfa, L., Sofara, A., Sylla, M., Traoré, M., Diop, A.B., Diop, O. and Dolo, A. (2011) Prevention of Mother to Child HIV Transmission in an African Hospital, Bamako-Mali. Mali Médical, 26, 18-22.

[2] Wei, R., Msamanga, G.I., Spielgelman, D., Hertzmark, E., Baylin, A., Manji, K. and Fawzi, W.W. (2004) Association between Low Birth Weight and Infant Mortality in Children Born to Human Immunodeficiency Virus 1-Infected Mothers in Tanzania. The Pediatric Infectious Disease Journal, 23, 530-535. https://doi.org/10.1097/01.inf.0000129691.42964.eb

[3] Sombie, I., Nacro, B., Tiendrébéogo, S., Dao, B., Cartoux, M., Méda, N., Ky-Zerbo, O., Dabis, F. and Mandelbrot, L. (1999) Maternal HIV Infection and the Anthropometric of Children at Birth in Burkina Faso. Cahier Santé, 9, 173-177.

[4] Taha, T.E.T., Dallabetta, G.A., Canner, J.K., et al. (1995) The Effect of Human Immunodeficiency Virus Infection on Birth Weight, and Infant and Child Mortality in Urban Malawi. International Journal of Epidemiology, 24, 1022-1029. https://doi.org/10.1093/ije/24.5.1022

[5] Bulterys, M., Chao, A., Munyemana, S., et al. (1994) Maternal Human Immunodeficiency Virus 1 Infection and Intrauterine Growth. A Prospective Cohort Study in Butare, Rwanda. The Pediatric Infectious Disease Journal, 13, 94-100. https://doi.org/10.1097/00006454-199402000-00003

[6] Timmerman, M., Chomba, E.N., Ndinmya-Achola, J., Plummer, F.A., Coppen, M. and Plot, P. (1994) Maternal Human Immunodeficiency Virus-1 Infection and Pregnancy Outcome. Obstetrics \& Gynecology, 83, 495-501. https://doi.org/10.1097/00006250-199404000-00002

[7] Ryder, R.W., Nsa, W., Hassig, S.E., et al. (1989) Perinatal Transmission of Human Immunodeficiency Virus Type 1 to Infants of Seropositive Women in Zaire. The New England Journal of Medicine, 330, 1637-1642. https://doi.org/10.1056/NEJM198906223202501

[8] Tonwe-Gold, B., Ekouévi, K.D., Viho, I., Amani-Bosse, C., Touré, S., Coffie, A.P., Rouet, F., Becquet, R., Leroy, V., El-Sadr, W.M., Abram, J.E. and Dabis, F. (2007) Antiretroviral Treatment and Prevention of Peri Partum and Postnatal HIV Transmission in West Africa: Evaluation of a Two-Tiered Approach. PLoS Medicine, 4, e257. https://doi.org/10.1371/journal.pmed.0040257

[9] Minkoff, H.L., Henderson, C., Mendez, H., et al. (1990) Pregnancy Outcome among Mothers Infected with Human Immunodeficiency Virus and Uninfected Control Subjects. American Journal of Obstetrics and Gynecology, 163, 1598-1604. 
https://doi.org/10.1016/0002-9378(90)90635-K

[10] Lawn, J.E., Cousens, S. and Zupan, J. (2005) 4 Million Neonatal Deaths When? Where? Why? The Lancet, 365, 891-900. https://doi.org/10.1016/S0140-6736(05)71048-5

[11] Brahmbhatt, H., Bishai, D., Wabwire-Mangen, F., et al. (2002) Polygyny Maternal HIV Status and Child Survival: Rakai, Uganda. Social Science \& Medicine, 55, 585-592. https://doi.org/10.1016/S0277-9536(01)00189-7

[12] Diouf, A., Avril, A., Cissé, M.L., Bouaicha, J.C., Sow, F. and Cissé, G. (2005) Prevention of Mother to Child Transmission of the HIV in a Teaching Hospital in Dakar. Journal of African Society of Gynecology and Obstetrics, 6, 13-20.

[13] Ratchanee, M., Pattara, S., Shelp, F.P., Marui, E. and Yanai, H. (2008) Low Birth Weight Infants Born to HIV-Seropositive Mothers and HIV-Seronegative Mothers in Chiang Rai, Thailand. The Southeast Asian Journal of Tropical Medicine and Public Health, 39, 273-278.

[14] Kamenga, M., Manzila, T., Behets, F., Oxtoby, M., Brown, C., Sulu, M., Nelson, A.M., Edidi, B., Batter, V. and Davachi, F. (1991) Maternal HIV Infection and Mother Other Sexually Transmitted Diseases and Low Birth Weight in Zairian Children. International Conference of AIDS, 357.

[15] Martin, R., Boyer, P., Hammill, H., Peavy, H., Platzker, A., Settlage, R., Shah, A., Sperling, R., Tuomala, R. and Wu, M. (1997) Incidence of Premature Birth and Neonatal Respiratory Disease in Infants of HIV-Positive Mothers. The Journal of Pediatrics, 131, 851-856. https://doi.org/10.1016/S0022-3476(97)70032-5

[16] Dreyfus, M.I., Msamanga, G.I., Spiegelman, D., Hunter, D.J., Urassa, E.J.N., Hertzmark, E. and Fawzi, W.W. (2001) Determinants of Low Birth Weight among HIV-Infected Pregnant Women in Tanzania. The American Journal of Clinical Nutrition, 74, 814-826. https://doi.org/10.1093/ajcn/74.6.814

[17] Khuong-Josses, M.A., Khelil, N., Guillaume, A.S. and Ekoukou, D. (2002) Human Immunodeficiency Virus and Pregnancy: A Retrospective Study of 124 Women. Pathologie Biologie, 50, 544-546. https://doi.org/10.1016/S0369-8114(02)00343-7

[18] Machado, E.S., Hofer, C.B., Costa, T.T., Nogueira, S.A., Oliveira, R.H., Abreu, T.F., Evangelista, L.A., Farias, I.F., Mercadante, R.T., Garcia, M.F., Neves, R.C., Costa, V.M. and Lambert, J.S. (2009) Pregnancy Outcome in Women Infected with HIV-1 Receiving Combination Antiretroviral Therapy before versus after Conception. Sexually Transmitted Infections, 85, 82-87.

[19] Tuomala, R.E., Shapiro, D.E., Mofenson, L.M., Bryson, Y., Culnane, M., Hughes, M.D., O'sullivan, M.J., Scott, G., Stek, A.M., Wara, D. and Bultery, M. (2002) Antiretroviral Therapy during Pregnancy and Risk of Adverse Outcome. The New England Journal of Medicine, 346, 1863-1870.

[20] Townsend, C.L., Cortina-Borja, M., Peckham, C.S. and Tookey, P.A. (2007) Antiretroviral Therapy and Premature Delivery in Diagnosed HIV-Infected Women in the United Kingdom and Ireland. AIDS, 21, 1019-1026.

[21] Chen, J.Y., Ribaudo, H.J., Souda, S., Parekh, N., Ogwu, A., Lockman, S., Powis, K., Dryden-Peterson, S., Creek, T., Jimbo, W., Madidimalo, T., Makhema, J., Essex, M. and Shapiro, R.L. (2012) Highly Active Antiretroviral Therapy and Adverse Birth Outcomes among HIV-Infected Women in Botswana. The Journal of Infectious Diseases, 206, 1695-1705. https://doi.org/10.1093/infdis/jis553

[22] Milogo-Traoré, F., Lankoandé, J. and Ouoba, R. (2008) Mother to Child Prevention against VIH in Health District of Kossodo (Burkina Faso). Revue Médicale de Bruxelles, 29, 153-158. 